\title{
$a b$ initio STUDY OF PHOTOCHEMICAL DECOMPOSITION MECHANISM OF TRIPHENYLSULFONIUM SALTS FOR KrF EXCIMER LASER EXPOSURE
}

\author{
NORIHITO OHMORI, YOSHIKAZU NAKAZONO, EIICHI ARAKI, \\ MASAYUKI HATA, TADATSUGU HOSHINO and MINORU TSUDA \\ Laboratory of Physical Chemistry, Faculty of Pharmaceutical Sciences, \\ Chiba University, Chiba 263, JAPAN
}

\section{Introduction}

Triphenylsulfonium salt is one of the most important photoinitiators in industry as photoacid generator (PAG) in the process of $\mathrm{KrF}$ excimer laser lithography [1, 2]. For this reason, many research papers have been published on the photochemical acid generation mechanism from this compound [2-6].

It was found theoretically there are two ways of photochemical acid generation from triphenylsulfonium salts; i.e., one is the process via photochemical isomerization $[5,6]$ and the other via photochemical decomposition [5]. In experimental research, only the decomposition mechanism was considered $[1,2,4]$, where the photochemical reaction product in the initial step is a phenyl radical [4] or a phenyl cation [2].

In this paper, ab initio molecular orbital-CI calculation was performed in order to elucidate the decomposition mechanism and the reaction product was identified in each of the excited states.

\section{Method of Calculation}

The same methods were used as described in another paper in this issue [7].

\section{Results and Discussions}

\subsection{Photochemical Decomposition Mechanism of Triphenylsulfonium}

The potential energy changes in the excited singlet states $\mathrm{S}_{1} \sim \mathrm{S}_{15}$ were calculated by $\mathrm{S}-\mathrm{CI}$ method with $3-21 G^{*}$ basis set following the decomposition process (1) and shown in Fig. 1, where the

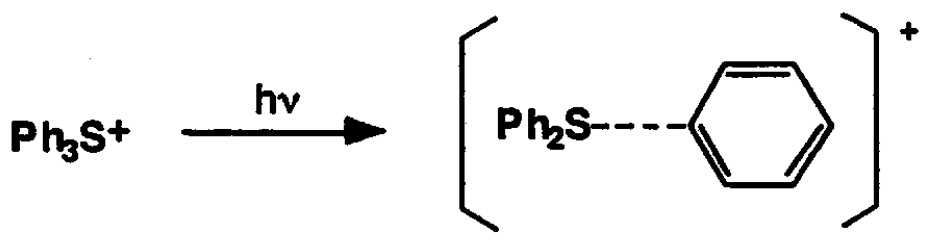




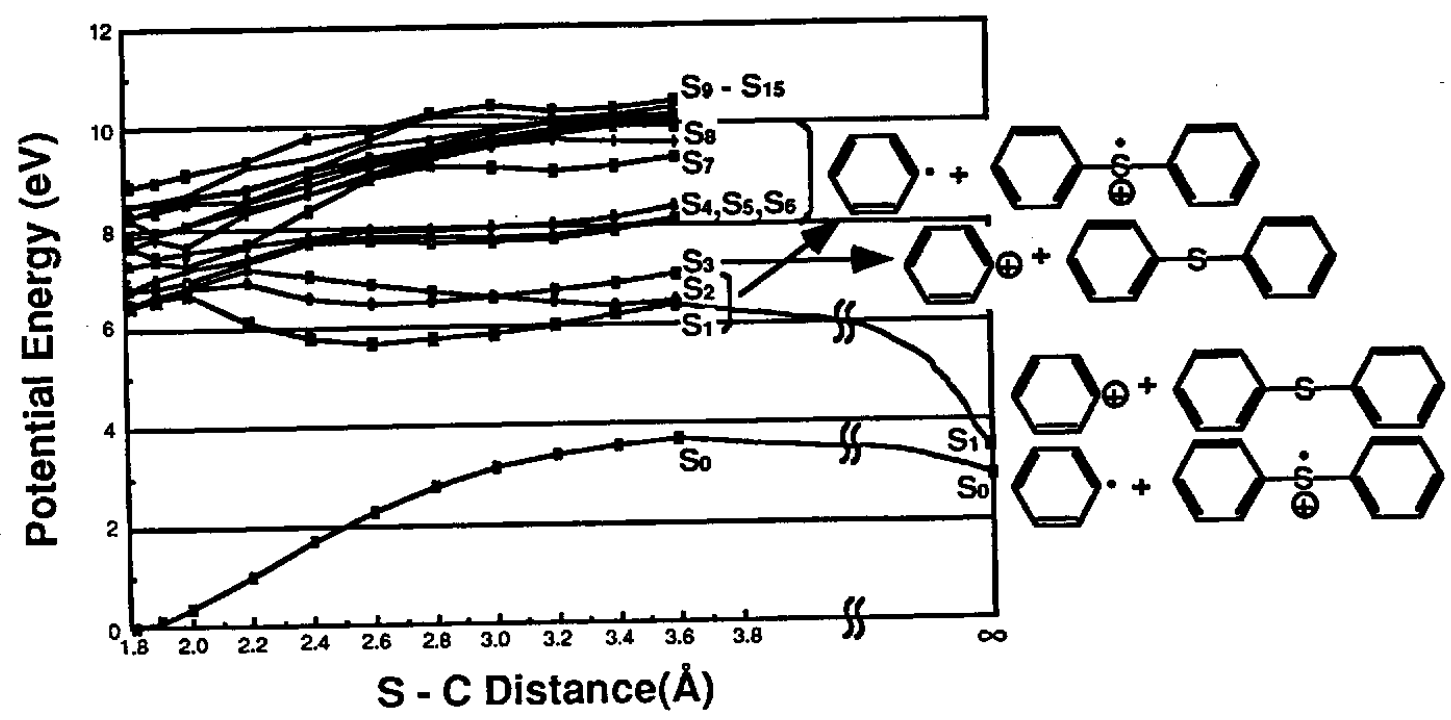

Fig. 1. Potential energy changes following the S-C separation in the reaction (1) along the lowest and shortest potential energy path of $\mathrm{Ph}_{3} \mathrm{~S}^{+}$in the ground singlet state $\mathrm{S}_{0}$. S-CI calculation using 3-21G ${ }^{*}$ basis set.

potential energy changes in the ground singlet state $S_{0}$ is the lowest energy path along the S-C distance separation in the reaction (1). The potential energy increases monotonously following the decomposition process (1) in the ground state $S_{0}$. In the lower-lying excited singlet state $S_{1} \sim S_{15}$, the potential energies increase at the initial stage of the $\mathrm{S}-\mathrm{C}$ distance separation except the 7 th and 10th excited states $\left(S_{7}\right.$ and $\left.S_{10}\right)$. The lowest excited singlet state $S_{1}$ is favorable for the decomposition after the S-C separation becomes longer than $2.0 \AA$. Tentatively assumed that this curve $S_{1}$ is the lowest potential energy path, the activation energy is $3.57 \mathrm{kcal} / \mathrm{mol}$ which is the detailed calculation results in the initial stage of the reaction (1). The $254 \mathrm{~nm} \mathrm{KrF}$ excimer laser light excites triphenylsulfonium $\mathrm{Ph}_{3} \mathrm{~S}^{+}$to its 4 th and 5th excited state $\left(\mathrm{S}_{4}\right.$ and $\left.\mathrm{S}_{5}\right)$. Since $\mathrm{S}_{4}$ and $\mathrm{S}_{5}$ have monotonously increasing potential energy curves along the S-C separation, the internal conversion from $S_{4}$ or $S_{5}$ to $S_{1}$ must be assumed to occur after the S-C separation becomes longer than $2.0 \AA$. Tentatively provided that the curve $S_{4}$ shows the lowest potential energy change, the activation energy is $9.02 \mathrm{kcal} / \mathrm{mol}$ for the decomposition process (1) which takes place from the $\mathrm{S}_{4}$ via the internal conversion to $S_{1}$.

The potential energy elevator in each of the excited singlet states at the initial stage of the S-C separation (1) is the characteristic of aromatic sulfonium $\mathrm{Ar}_{3} \mathrm{~S}^{+}$. Because of this characteristic, the isomerized products may be produced in high yield in the photochemical reaction of triphenylsulfonium salt in experiments [2]. As shown in Fig. 2 for $\mathrm{SH}_{3}{ }^{+}$as well as in another paper for $\left(\mathrm{CH}_{3}\right)_{3} \mathrm{~S}^{+}$[7], the potential energies of these sulfoniums in the lower-lying excited singlet 


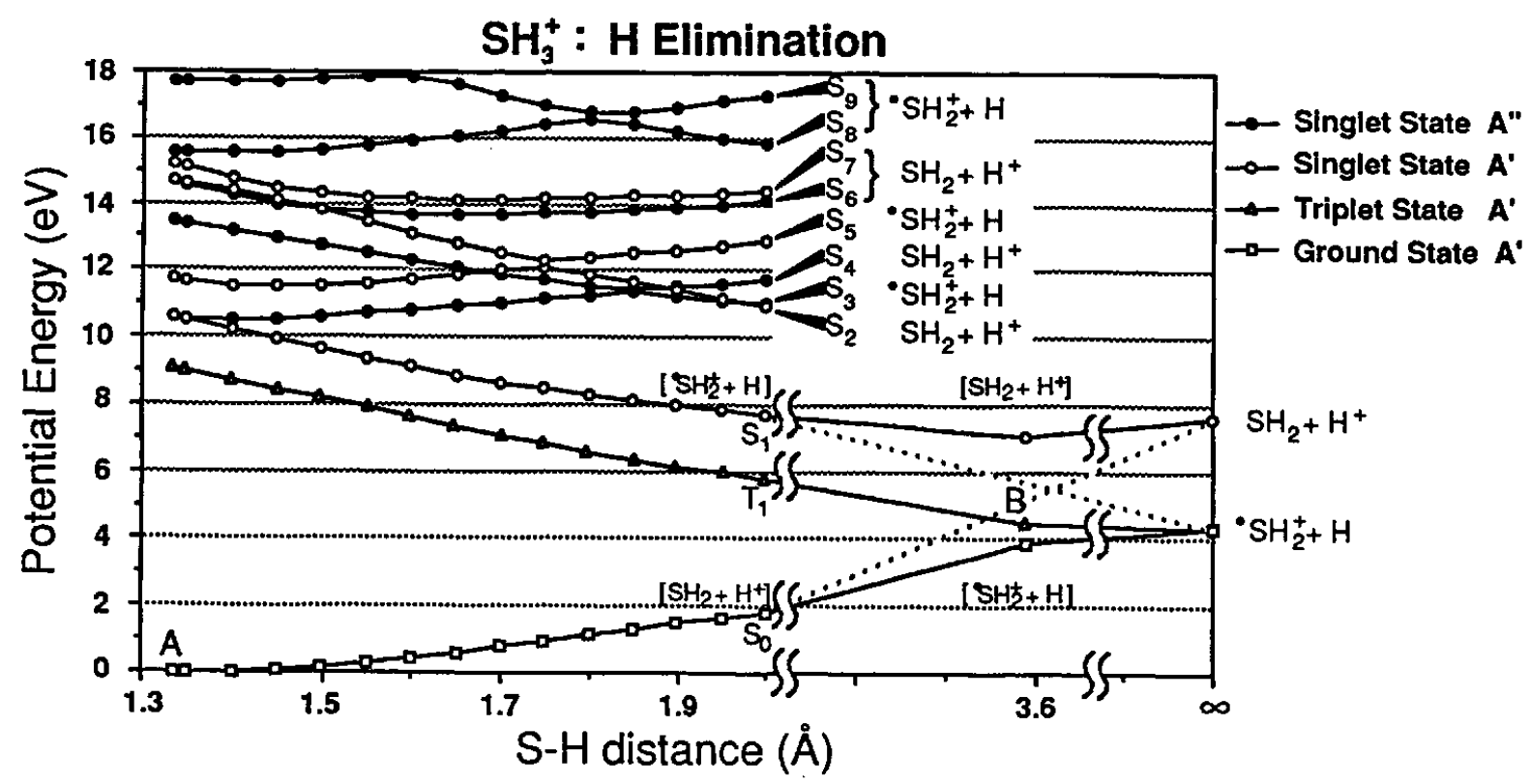

Fig. 2. Potential energy changes following the decomposition of $\mathrm{SH}_{3}{ }^{+}$along the lowest and shortest potential energy path of the ground singlet state $\mathrm{S}_{0}$. SDTQ-CI calculation using $6-31 \mathrm{G}^{* *}$ basis set with $4 \mathrm{~s}$ and $4 \mathrm{p}$ Rydberg orbitals.

state decrease monotonously

for the S-C separation and the photochemical decompositions of these sulfoniums are expected to occur spontaneously.

A big question arose when we examined the photochemical reaction products in each of the ground and excited states. At 3.6 ̊̊ of the S-C distance in Fig. 1, phenyl cation and diphenylsulfide $\left(\mathrm{Ph}^{+}+\mathrm{Ph}_{2} \mathrm{~S}\right)$ is produced in the ground singlet state, but phenyl radical and diphenylsulfide cation radical $\left(\mathrm{Ph}^{\bullet}+\mathrm{Ph}_{2} \mathrm{~S}^{+\bullet}\right)$ is generated from the lowest singlet state $\mathrm{S}_{1}$ as well as in the lowest triplet state $T_{1}$. The products from $S_{2} \sim S_{15}$ at this $S-C$ distance were indicated in Fig.1 for each of the excited singlet states. However, when the decomposition reaction (1) has been completed, $(\mathrm{Ph}+$ $\left.\mathrm{Ph}_{2} \mathrm{~S}^{+\bullet}\right)$ has lower potential energy than $\left(\mathrm{Ph}^{+}+\mathrm{Ph}_{2} \mathrm{~S}\right)$; i.e., $\left(\mathrm{Ph}^{\bullet}+\mathrm{Ph}_{2} \mathrm{~S}^{+\bullet}\right)$ is generated from the ground singlet state $S_{0}$ and the lowest triplet state $T_{1}$, but $\left(\mathrm{Ph}^{+}+\mathrm{Ph}_{2} \mathrm{~S}\right)$ is produced from the lowest excited singlet state $S_{1}$. What is the origin of this exchange of the final products between the different electronic states occurred during the decomposition process of triphenylsulfonium? For making this mystery clear, more precise CI calculations are required.

\subsection{Photochemical Decomposition Mechanism of $\mathrm{SH}_{3}{ }^{+}$- A Precise Research}

Because of the difficulty in the exact determination of the excited states of a molecule which contains a large number of electrons by ab initio $\mathrm{CI}$ calculation, $\mathrm{SH}_{3}{ }^{+}$was chosen as a model compound for precise research. The lowest potential energy change for the decomposition reaction $\mathrm{SH}_{3}+\ldots\left(\mathrm{SH}_{2}+\mathrm{H}^{+}\right)$was determined in the ground singlet state $\mathrm{S}_{0}$. The vertical excitation 
energies from the ground state to the lower-lying excited states were calculated for the determination of the potential energy changes following the photochemical decomposition process through the excited singlet states $S_{1} \sim S_{9}$ (Fig. 2). The lowest potential energy change in the lowest triplet state $\mathrm{T}_{1}$ is also shown in Fig. 2 although the structure change is different from that in the singlet state $\mathrm{S}_{0}$. The precise energy levels in the singlet states were calculated by SDTQ-CI method. The photochemical decomposition products from the lowest excited singlet state $\mathrm{S}_{1}$ are $\mathrm{SH}_{2}$ and a proton whereas those from the ground state $S_{0}$ as well as the lowest triplet state $\mathrm{T}_{1}$ are $\mathrm{SH}_{2}{ }^{+}$and a hydrogen atom because of a strong configuration interaction among the ground state $S_{0}$ and many of excited singlet states $\mathrm{S}_{\mathrm{n}}$. As shown in Fig. 2, $\mathrm{SH}_{2}$ and a proton are initially generated from the ground singlet state $\mathrm{S}_{0}$ at the $\mathrm{S}-\mathrm{H}$ distance of $2.0 \AA$. On the other hand, $\mathrm{SH}_{2}{ }^{+\bullet}$ and a hydrogen atom are produced from the lowest excited singlet state $S_{1}$. The mixing of electronic states of $\mathrm{S}_{0} \mathrm{~S}_{\mathrm{n}}$, however, occurs strongly at the longer distance of the S-H bond than $2.0 \AA$, and finally $\mathrm{SH}_{2}{ }^{+\bullet}$ and a hydrogen atom are produced from the excited singlet state $\mathrm{S}_{1}$, but $\mathrm{SH}_{2}{ }^{+}$and a hydrogen atom are generated from the ground singlet state $S_{0}$, respectively. This situation is exactly the same as observed in the case of triphenylsulfonium $\mathrm{Ph}_{3} \mathrm{~S}^{+}$. The strong interaction among the ground and excited singlet states is the origin of the exchange of the final product. This phenomenon was observed also in the case of trimethylsulfonium [7]. One should note that the final products were already generated at the S-H distance of 3.6 $\AA$ (Fig. 2). In the lowest triplet state $\mathrm{T}_{1}$, $\mathrm{SH}_{2}{ }^{+} \cdot$ and a hydrogen atom are produced simply along the potential energy change. When the separation of $\mathrm{S}-\mathrm{H}$ bond is completed, the sum of the potential energies of $\mathrm{SH}_{2}{ }^{+\bullet}$ and $\mathrm{H}$ is lower than that of $\mathrm{SH}_{2}$ and $\mathrm{H}^{+}$(Fig. 2).

\section{References}

1. H. Ito and C. G. Willson, Polym. Eng. Sci., 23 (1983) 1012.

2. J. L. Dektar and N. P. Hacker, J. Am. Chem. Soc., 112 (1990) 6004.

3. T. Ueno, H. Shiraishi, S. Uchino, T. Sakamizu and T. Hattori, J. Photopolym. Sci. Technol., 7 (1994) 397.

4. S. P. Pappas, J. Iwaging Technol., 11 (1985) 146.

5. S. Oikawa, N. Fujii, M. Hata and M. Tsuda, J. Photopolym. Sci. Technol., 7 (1994) 483.

6. N. Ohmori, Y. Nakazono, A. Tsujino, M. Hata, S. Oikawa and M. Tsuda, J. Photopolym. Sci. Technol., 8 (1995) 653.

7. Y. Nakazono, E. Araki, N. Ohmori, M. Hata, S. Oikawa and M. Tsuda, J. Photopolym. Sci. Technol., 9 (1996) 693. 